\title{
BMJ Open Do biomass fuel use and consumption of unsafe water mediate educational inequalities in stillbirth risk? An analysis of the 2007 Ghana Maternal Health Survey
}

\author{
A Kofi Amegah, ${ }^{1}$ Simo Näyhä, ${ }^{2}$ Jouni J K Jaakkola ${ }^{2}$
}

To cite: Amegah AK, Näyhä S, Jaakkola JJK. Do biomass fuel use and consumption of unsafe water mediate educational inequalities in stillbirth risk? An analysis of the 2007 Ghana Maternal Health Survey. BMJ Open 2017;7: e012348. doi:10.1136/ bmjopen-2016-012348

- Prepublication history and additional material is available. To view please visit the journal (http://dx.doi.org/ 10.1136/bmjopen-2016012348).

Received 19 April 2016 Revised 28 November 2016 Accepted 17 January 2017

CrossMark

\footnotetext{
${ }^{1}$ Public Health Research Group, Department of Biomedical Sciences, School of Allied Health Sciences, University of Cape Coast, Cape Coast, Ghana ${ }^{2}$ Center for Environmental and Respiratory Health Research, Faculty of Medicine, University of Oulu, Oulu, Finland
}

\section{Correspondence to} Dr A Kofi Amegah; aamegah@ucc.edu.gh.

\begin{abstract}
Background: Numerous studies have explored the association between educational inequalities and stillbirth but most have failed to elaborate how low educational attainment leads to an increased risk of stillbirth. We hypothesised that use of biomass fuels and consumption of unsafe water related to low educational attainment could explain the stillbirth burden in Ghana attributable to socioeconomic disadvantage.
\end{abstract}

Methods: Data from the 2007 Ghana Maternal Health Survey, a nationally representative population-based survey were analysed for this study. Of the10 370 women aged 15-49 years interviewed via structured questionnaires for the survey, 7183 primiparous and multiparous women qualified for inclusion in the present study.

Results: In a logistic regression analysis that adjusted for age, area of residence, marital status and ethnicity of women, lower maternal primary education was associated with a $62 \%(0 \mathrm{R}=1.62 ; 95 \% \mathrm{Cl} 1.04$ to 2.52) increased lifetime risk of stillbirth. Biomass fuel use and consumption of unsafe water mediated $18 \%$ and $8 \%$ of the observed effects, respectively. Jointly these two exposures explained $24 \%$ of the observed effects. The generalised additive modelling revealed a very flat inverted spoon-shaped smoothed curve which peaked at low levels of schooling (2-3 years) and confirms the findings from the logistic regression analysis.

Conclusions: Our results show that biomass fuel use and unsafe water consumption could be important pathways through which low maternal educational attainment leads to stillbirths in Ghana and similar developing countries. Addressing educational inequalities in developing countries is thus essential for ensuring household choices that curtail environmental exposures and help improve pregnancy outcomes.

\section{INTRODUCTION}

Stillbirth, the intrauterine death of any conceptus at any time during pregnancy, ${ }^{1}$ is a major public health concern in developing

\section{Strengths and limitations of this study}

- The study was based on a large and representative sample.

- The education-stillbirth relationship was illustrated in terms of smoothed curves of school years.

- The exposure assessment method applied has limitations but has been widely used in environmental epidemiological studies and shown to be very good proxy measures of exposure.

- Exposure misclassification was possible in the study owing to the inability to ascertain whether cooking fuel choices and drinking water sources of the households remained relatively stable throughout the pregnancies of the study participants.

countries. An estimated 3.2 million stillbirths occur worldwide annually with $98 \%$ of these stillbirths found in developing countries. ${ }^{2}$ Important causes of stillbirths globally are asphyxia and infection associated with obstructed or prolonged labour, preeclampsia and eclampsia, chorioamnionitis, syphilis, malaria and poor nutritional status. ${ }^{3}$ Stillbirth occurrence has been noted to be much higher among ethnic minority, disadvantaged, marginalised and rural populations. $^{4-6}$ This observation demonstrates the important role of socioeconomic factors in the aetiology of stillbirth.

The risk factors of stillbirth in low-income countries are associated with poverty ${ }^{7}$ including solid fuel use and consumption of unsafe water. Many households in developing countries rely on ground and surface water resources due to limited access to pipe-borne water, erratic supply, and high connection and utility charges. These water resources are often polluted by mining and agricultural activities, as well as nearby pit latrines which 
are also in widespread use in developing countries. Mining activities, especially in unregulated mines, lead to deposition/leaching of substantial amounts of chemicals such as cyanide and sulfuric acid, and heavy metals into nearby water bodies. Agricultural runoffs also introduce sediments, pesticides, fertilizers and pathogens into water bodies. Pit latrines have also been widely documented to leach microbial and chemical contaminants including coliforms, Escherichia coli, faecal streptococci, ammonia, nitrates and nitrites into groundwater resources. ${ }^{8}$ Poverty further hampers many households from treating these unwholesome water resources before usage. Solid fuels are also the predominant cooking fuel in developing countries owing to poverty and limited access to clean fuels. ${ }^{9}$ Bonjour et $a l^{10}$ estimated the proportion of households in Africa and Southeast Asia relying on solid fuels for cooking to be more than $60 \%$. Studies have associated use of solid fuels ${ }^{11}$ and consumption of contaminated drinking water ${ }^{12-14}$ with stillbirth and other adverse pregnancy outcomes.

Socioeconomic characteristics including educational attainment are well documented to have strong effects on health outcomes including pregnancy outcomes. Several studies mostly emanating from high-income countries have explored the relationship between educational attainment and stillbirth but most have failed to elaborate how low educational attainment leads to an increased risk of stillbirth. We hypothesised that household use of biomass fuels and consumption of unsafe water related to low educational attainment could explain the stillbirth burden in Ghana attributable to socioeconomic disadvantage. As noted by Kramer, ${ }^{15}$ research that identifies and quantifies the causal pathways and mechanisms through which social disadvantage leads to higher risks of adverse pregnancy outcomes may help to reduce disparities and improve pregnancy outcomes across the entire socioeconomic spectrum.

We relied on data from the 2007 Ghana Maternal Health Survey (GMHS), ${ }^{16}$ a nationally representative population-based survey, that collected comprehensive information at the household and individual woman's level on maternal health issues including pregnancies, stillbirths, abortions and miscarriages and maternal deaths in the country.

\section{METHODS}

Data from the 2007 GMHS $^{16}$ were analysed for this study. GMHS was a nationally representative populationbased survey that collected comprehensive information on maternal health and mortality in the country to provide baseline information for the Reducing Maternal Morbidity and Mortality (R3M) programme initiated in three regions (Greater Accra, Eastern, Ashanti) of Ghana in 2006. The survey design of GMHS involved the selection of 1600 primary sampling units (clusters) from the 10 administrative regions of the country, across urban and rural areas. The primary sampling units consisted of wards or subwards drawn from the 2001 population census.

Data collection was carried out in two phases with data for the present study deriving from the second phase. In the second phase, 400 clusters were randomly selected from the 1600 clusters with a long household questionnaire administered in 10858 households (response rate, $98.8 \%$ ) randomly selected from these clusters. These households were selected independently from the 227715 households identified in the first phase (from the 1600 clusters) for profiling maternal deaths. Also in the second phase, a women's questionnaire was administered to 10370 women aged 15-49 years (response rate, $97.6 \%$ ) identified from the 10858 households. The long household questionnaires collected information on the demographic and socioeconomic characteristics of members of the households sampled, whereas the women's questionnaire gathered information on a wide range of maternal health-related issues including live births, stillbirths, abortions and miscarriages and usage of health services in relation to these events.

To be eligible for inclusion in the present study, a woman must have given birth at least once (ie, primiparous and multiparous women). Of the 10370 women aged 15-49 years, $7183(69.3 \%)$ primiparous and multiparous women were eligible for the present study.

A flow chart of the survey sampling procedure and mothers included in the present study is depicted in figure 1 .

\section{Ascertainment of educational attainment}

In the women's questionnaire, respondents were asked whether they have ever attended school and if they

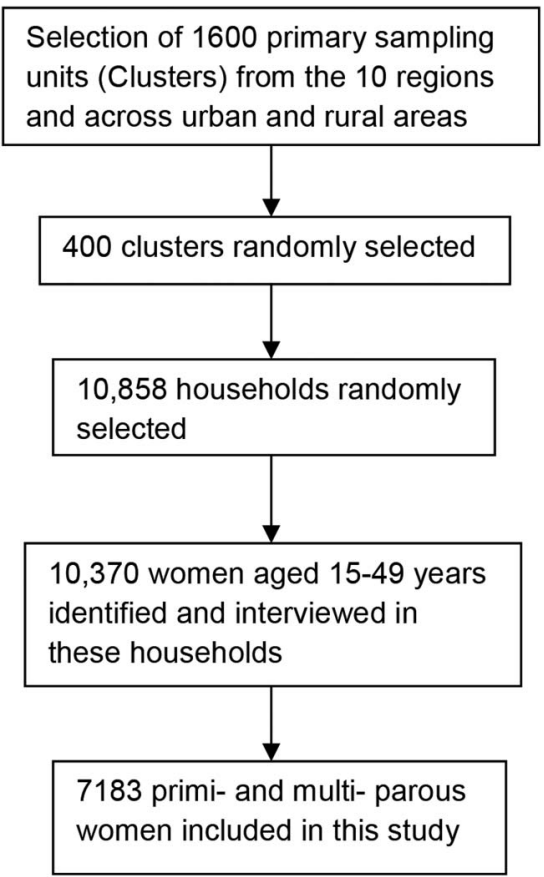

Figure 1 Flow chart of the survey sampling procedure and mothers included in present study. 
answered 'yes' they were further asked about the highest level of school they attended and the highest grade they completed at that level. Maternal education was treated as a continuous and categorical variable in the analysis.

In treating maternal educational attainment as a continuous variable, we combined the information obtained from mothers who reported ever attending school into years of schooling (1-15 years). Mothers who never attended school were ranked zero on this scale.

The following levels of maternal education were applied in the analysis: none, lower primary (1-4 years of schooling), upper primary (5-6 years of schooling), some middle/junior secondary school (JSS) (7-8 years of schooling), completed middle school/JSS (9 years of schooling), secondary/senior secondary school (SSS) (10-12 years of schooling) and higher ( $\geq 13$ years of schooling).

\section{Assessment of exposure}

Maternal exposure to household air pollution (HAP) was assessed by the type of fuel used by households for cooking. This information was obtained from the long household questionnaire. In this questionnaire, household heads were asked, "What type of fuel does your household mainly use for cooking?' Mothers living in households using electricity, liquefied petroleum gas (LPG) and natural gas served as the reference category with those residing in households using charcoal, firewood and straw/shrubs/grass representing the exposed category. Kerosene, a non-solid fuel but with uncertainties about its cleanliness was excluded from the reference category. Very few households used coal/lignite, a non-biomass fuel for cooking and were thus excluded from the analysis.

Maternal exposure to contaminated drinking water was ascertained by the type of drinking water sources of the household. This information was also obtained from the long household questionnaire in which household heads were asked, 'What is the main source of drinking water for members of your household?' Mothers residing in households using piped and bottled/sachet water served as the reference category with those living in households sourcing water from surface (rivers, streams, lakes, dams, ponds, etc) and ground (wells, boreholes) waters representing the exposed categories. Mothers in households using spring water, rainwater and tanker water were excluded from the analysis because of the small number of households using these water resources.

\section{Outcome of interest}

The outcome of interest was lifetime experience of stillbirth (yes vs no) among primiparous and multiparous women. This information was extracted from the women's questionnaire where mothers were asked whether they have ever given birth in late pregnancy (7 months or more) to a dead child and if they answered 'yes', they were further asked about the number of stillbirths they have had in their lifetime.

\section{Covariates}

The following core potential confounders were adjusted for in the analysis: area of residence (urban, rural), age of woman, marital status and ethnicity.

\section{Ethical consideration}

Informed consent was obtained from all the participants before the interview.

\section{Statistical analysis}

We first described the education-stillbirth relationship in terms of relative risk by educational categories using logistic regression (PROC LOGISTIC). PROC LOGISTIC was used to estimate the effects of maternal education on the risk of stillbirth (yes, coded 1 vs no, coded 0 ) in a woman's lifetime, and to also establish whether a gradient in the risk exists. The analysis was adjusted for the core potential confounders.

We performed a causal pathway analysis using the difference method $^{17}$ to establish the independent and joint mediating effect of biomass fuel use and consumption of unsafe drinking water in the observed educational differences in stillbirth risk. In brief, after controlling for the core confounders, biomass fuel use and unsafe water consumption were further independently and jointly added to the adjusted model with the mediation fractions computed using the formula below:

$$
\frac{\mathrm{OR}_{\text {adjusted }}-\mathrm{OR}_{\text {mediation }}}{1-\mathrm{OR}_{\text {adjusted }}} \times 100 \%
$$

where $O R_{\text {adjusted }}$ is the $\mathrm{OR}$ in the adjusted model and $O R_{\text {mediation }}$ is the OR in the independent and joint mediation models.

We next illustrated the education-stillbirth relationship in terms of cubic smoothing splines using generalised additive modelling (GAM) with three degrees of freedom (df). Three df were chosen after fitting six separate models $(\mathrm{df}=3,4,5,6,7$ and 8$)$ and identifying the model with $3 \mathrm{df}$ to have the best fit. The Akaike Information Criterion (AIC) was used to evaluate goodness of fit of the models fitted. AIC was estimated using the formula below:

$$
A I C=D(\theta)+2 p,
$$

where $\mathrm{D}(\theta)$ is the deviance and $p$ is the number of parameters (df) in the model. The model with the smaller AIC value was deemed a better fit. The AIC values are presented in online supplementary table S1.

GAM allowed maternal education to be applied as a continuous variable (school years), thereby increasing statistical power and enabling a better illustration of the predictor-risk relationship. Possible non-linearities in 
the maternal education data were explored by performing $\chi^{2}$ test of non-linearity. We stratified the curve fitting by urban and rural residence to ascertain whether there exist any marked differences.

SAS V.9.3 was used to perform all the analysis with the exception of the GAM which was performed with Stata 12.0.

\section{RESULTS}

The characteristics of the study population are presented in tables 1 and 2. Close to one-third (31.9\%) of the respondents were within the age group 20-39 years. More than half $(68.6 \%)$ of the women reported being married with very few $(6.4 \%)$ reporting that they have never been married. Close to half $(46.3 \%)$ of the study population were resident in the R3M regions (Greater Accra, Eastern and Ashanti) with $19 \%$ of the women living in the three northern regions (Northern, Upper East, Upper West). More than half $(58 \%)$ of the respondents were rural dwellers with about $17 \%$ of the respondents identified as city dwellers. Majority of the women (75\%) were Christians with Muslims making up about $16 \%$ of the study respondents. Close to half $(46 \%)$ of the women were Akans. Close to one-third (32.3\%) of the respondents had no formal education with only $2.1 \%$ of the women educated up to the tertiary level or higher.

Biomass fuel, notably charcoal and firewood were the dominant cooking fuels of respondent's households with $91 \%$ of households using these fuels. LPG was used by $8 \%$ of the respondent's households. Whereas among highly educated mothers, LPG was the dominant fuel used $(69 \%)$, among uneducated $(77 \%)$ and primary educated $(64 \%)$ mothers firewood was the fuel mostly used. Piped water $(40 \%)$ and well/borehole $(41 \%)$ were the dominant drinking water sources of the respondents. About $5 \%$ and $11 \%$ of the respondents used bottled/ sachet and surface water, respectively. Secondary (59\%) and highly $(64 \%)$ educated mothers patronised piped water mostly. A quarter of highly educated mothers used bottled/sachet water. Among uneducated mothers, 53\% accessed well/borehole water resources with $26 \%$ using piped water. Among primary and some middle school/ JSS-educated women, the proportion using piped and well/borehole water resources were about the same.

The gravidity status and lifetime stillbirth experience of the women interviewed are presented in table 3 . About $14 \%$ of the respondents were primigravida. About $6 \%$ of the respondents reported experiencing stillbirth in their lifetime with a small proportion $(13 \%)$ of them experiencing this occurrence more than once. Uneducated mothers and mothers who completed middle/JSS recorded the highest proportion of lifetime stillbirths; $32 \%$ and $26 \%$, respectively.

Table 4 and online supplementary S2 present the ORs for the association between maternal education and lifetime stillbirth experience calculated from logistic
Table 1 Demographic and background characteristics of the study respondents $(n=7183)$

\begin{tabular}{|c|c|}
\hline Characteristic & No. (\%) \\
\hline \multicolumn{2}{|l|}{ Age (years)* } \\
\hline$<20$ & 247 (3.4) \\
\hline 20-29 & 2293 (31.9) \\
\hline 30-39 & $2713(37.8)$ \\
\hline$>39$ & $1930(26.9)$ \\
\hline \multicolumn{2}{|l|}{ Marital status $†$} \\
\hline Married & 4925 (68.6) \\
\hline Cohabitation & $878(12.2)$ \\
\hline Never married & $457(6.4)$ \\
\hline Divorced/separated & $721(10.0)$ \\
\hline Widowed & $200(2.8)$ \\
\hline Missing & $2(0.03)$ \\
\hline \multicolumn{2}{|l|}{ Region of residence } \\
\hline Western & $569(7.9)$ \\
\hline Central & $642(8.9)$ \\
\hline Greater Accra & $1071(14.9)$ \\
\hline Volta & $590(8.2)$ \\
\hline Eastern & $1084(15.1)$ \\
\hline Ashanti & 1173 (16.3) \\
\hline Brong Ahafo & $684(9.5)$ \\
\hline Northern & $637(8.9)$ \\
\hline Upper East & $409(5.7)$ \\
\hline Upper West & $324(4.5)$ \\
\hline \multicolumn{2}{|l|}{ Area of residencef } \\
\hline City & $1249(17.4)$ \\
\hline Town & $1782(24.8)$ \\
\hline Rural & $4152(57.8)$ \\
\hline \multicolumn{2}{|l|}{ Education } \\
\hline None & $2316(32.3)$ \\
\hline Lower primary (1-4 years of schooling) & $789(11.0)$ \\
\hline Upper primary (5-6 years of schooling) & $801(11.2)$ \\
\hline Some middle/JSS (7-8 years of schooling) & $699(9.7)$ \\
\hline Completed middle/JSS (9 years of schooling) & $1941(27.0)$ \\
\hline Secondary/SSS (10-12 years of schooling) & $485(6.8)$ \\
\hline Higher ( $\geq 13$ years of schooling) & $151(2.1)$ \\
\hline Missing & $1(0.01)$ \\
\hline \multicolumn{2}{|l|}{ Religion } \\
\hline Christian & $5364(74.7)$ \\
\hline Moslem & $1142(15.9)$ \\
\hline Traditional/spiritualist & $284(4.0)$ \\
\hline Other & $5(0.1)$ \\
\hline No religion & $385(5.4)$ \\
\hline Missing & $3(0.04)$ \\
\hline \multicolumn{2}{|l|}{ Ethnic group§ } \\
\hline Akan & $3303(46.0)$ \\
\hline Ga/Dangme & $624(8.7)$ \\
\hline Ewe & $985(13.7)$ \\
\hline Guan & $155(2.2)$ \\
\hline Mole-Dagbani & $683(9.5)$ \\
\hline Grussi & $341(4.8)$ \\
\hline Gruma & $416(5.8)$ \\
\hline Hausa & 77 (1.1) \\
\hline Other & 597 (8.3) \\
\hline Missing & $2(0.03)$ \\
\hline
\end{tabular}

Covariates:

${ }^{*}$ Age group $20-29$ years.

†Married/cohabitation.

‡Urban (city and town).

$\S$ Akan served as reference category.

JSS, Junior Secondary School; SSS, Senior Secondary School. 
Table 2 Cooking fuel choices and drinking water sources of study respondents households ( $n=7182$ )

\begin{tabular}{|c|c|c|c|c|c|c|c|c|}
\hline & $\begin{array}{l}\text { None } \\
\mathrm{n}(\%)\end{array}$ & $\begin{array}{l}\text { Lower primary } \\
\text { n (\%) }\end{array}$ & $\begin{array}{l}\text { Upper primary } \\
\text { n (\%) }\end{array}$ & $\begin{array}{l}\text { Some middle/JSS } \\
\text { n (\%) }\end{array}$ & $\begin{array}{l}\text { Completed middle/JSS } \\
\text { n (\%) }\end{array}$ & $\begin{array}{l}\text { Secondary/SSS } \\
\text { n (\%) }\end{array}$ & $\begin{array}{l}\text { Higher } \\
\text { n (\%) }\end{array}$ & $\begin{array}{l}\text { Total } \\
\text { n (\%) }\end{array}$ \\
\hline \multicolumn{9}{|l|}{ Type of cooking fuel } \\
\hline Electricity & $1(0.04)$ & $1(0.13)$ & $0(0.00)$ & $0(0.00)$ & $2(0.10)$ & $3(0.62)$ & $4(2.65)$ & $11(0.15)$ \\
\hline LPG & $14(0.60)$ & $24(3.04)$ & 29 (3.62) & $30(4.29)$ & 232 (11.95) & $158(32.58)$ & $104(68.87)$ & 591 (8.23) \\
\hline Natural gas & $1(0.04)$ & $1(0.13)$ & $0(0.00)$ & $1(0.14)$ & $3(0.15)$ & $0(0.00)$ & $1(0.66)$ & $7(0.10)$ \\
\hline Kerosene & $0(0.00)$ & $0(0.00)$ & $2(0.25)$ & $1(0.14)$ & $7(0.36)$ & $0(0.00)$ & $0(0.00)$ & $10(0.14)$ \\
\hline Coal/lignite & $0(0.00)$ & $0(0.00)$ & $1(0.12)$ & $0(0.00)$ & $0(0.00)$ & $1(0.21)$ & $0(0.00)$ & $2(0.03)$ \\
\hline Charcoal & $492(21.24)$ & $256(32.45)$ & $334(41.70)$ & 267 (38.20) & 872 (44.93) & $221(45.57)$ & 34 (22.52) & $2476(34.48)$ \\
\hline Firewood & 1789 (77.25) & $504(63.88)$ & $433(54.06)$ & $397(56.80)$ & $819(42.19)$ & $100(20.62)$ & $8(5.30)$ & 4050 (56.39) \\
\hline Straw/shrub/grass & $18(0.78)$ & $0(0.00)$ & $2(0.25)$ & $1(0.14)$ & $0(0.00)$ & $1(0.21)$ & $0(0.00)$ & $22(0.31)$ \\
\hline No cooking & $0(0.00)$ & $3(0.38)$ & $0(0.00)$ & $2(0.29)$ & $5(0.26)$ & $1(0.21)$ & $0(0.00)$ & $11(0.15)$ \\
\hline Missing & $1(0.04)$ & $0(0.00)$ & $0(0.00)$ & $0(0.00)$ & $1(0.05)$ & $0(0.00)$ & $0(0.00)$ & $2(0.03)$ \\
\hline \multicolumn{9}{|l|}{ Source of drinking water } \\
\hline Piped water & $606(26.17)$ & $290(36.76)$ & $325(40.57)$ & $276(39.48)$ & $959(49.41)$ & $287(59.18)$ & 97 (64.24) & $2840(39.54)$ \\
\hline Well/borehole & $1232(53.19)$ & $330(41.82)$ & $312(38.96)$ & $296(42.34)$ & $671(34.57)$ & $88(18.14)$ & $16(10.59)$ & $2945(41.00)$ \\
\hline Spring & $72(3.11)$ & $16(2.02)$ & $18(2.24)$ & $15(2.14)$ & $24(1.24)$ & $2(0.42)$ & $0(0.00)$ & $147(2.04)$ \\
\hline Surface water & 356 (15.37) & $112(14.20)$ & 98 (12.23) & $70(10.01)$ & $122(6.29)$ & $13(2.68)$ & $1(0.66)$ & $772(10.75)$ \\
\hline Rainwater & $9(0.39)$ & $4(0.51)$ & $6(0.75)$ & $6(0.86)$ & $24(1.24)$ & $3(0.62)$ & $0(0.00)$ & $52(0.72)$ \\
\hline Tanker truck & $8(0.35)$ & $10(1.27)$ & $4(0.50)$ & $1(0.14)$ & $9(0.46)$ & $4(0.82)$ & $0(0.00)$ & $36(0.50)$ \\
\hline Bottled/sachet water & $32(1.38)$ & $27(3.42)$ & $38(4.74)$ & $35(5.01)$ & $130(6.70)$ & $88(18.14)$ & 37 (24.50) & 387 (5.39) \\
\hline Other & $0(0.00)$ & $0(0.00)$ & $0(0.00)$ & $0(0.00)$ & $1(0.05)$ & $0(0.00)$ & $0(0.00)$ & $1(0.01)$ \\
\hline Missing & $1(0.04)$ & $0(0.00)$ & $0(0.00)$ & $0(0.00)$ & $1(0.05)$ & $0(0.00)$ & $0(0.00)$ & $2(0.03)$ \\
\hline
\end{tabular}

The education category had one missing value.

JSS, Junior Secondary School; SSS, Senior Secondary School. 
Table 3 Gravidity status and lifetime stillbirth experience of study respondents classified by maternal education

\begin{tabular}{|c|c|c|c|c|c|c|c|c|}
\hline & $\begin{array}{l}\text { None } \\
\mathbf{n}(\%)\end{array}$ & $\begin{array}{l}\text { Lower } \\
\text { primary } \\
\mathbf{n}(\%)\end{array}$ & $\begin{array}{l}\text { Upper } \\
\text { primary } \\
\mathbf{n}(\%)\end{array}$ & $\begin{array}{l}\text { Some } \\
\text { middle/ } \\
\text { JSS } \\
\mathrm{n}(\%) \\
\end{array}$ & $\begin{array}{l}\text { Completed } \\
\text { middle/ } \\
\text { JSS } \\
\mathrm{n}(\%) \\
\end{array}$ & $\begin{array}{l}\text { Secondary/ } \\
\text { SSS } \\
\mathrm{n}(\%)\end{array}$ & $\begin{array}{l}\text { Higher } \\
\text { n (\%) }\end{array}$ & $\begin{array}{l}\text { Total } \\
\mathrm{N}(\%) \\
\end{array}$ \\
\hline \multicolumn{9}{|l|}{ Gravidity } \\
\hline Primigravida & & & & & & & & $1029(14.3)$ \\
\hline Multigravida & & & & & & & & $6154(85.7)$ \\
\hline \multicolumn{9}{|c|}{ Lifetime stillbirth experience } \\
\hline No & $2183(32.3)$ & $727(10.8)$ & $764(11.3)$ & $658(9.7)$ & $1831(27.1)$ & $458(6.8)$ & $144(2.1)$ & $6766(94.2)$ \\
\hline Yes & $133(31.9)$ & $62(14.9)$ & $37(8.9)$ & $41(9.8)$ & $110(26.4)$ & $27(6.5)$ & $7(1.7)$ & $417(5.8)$ \\
\hline \multicolumn{9}{|c|}{ No. of stillbirths in lifetime } \\
\hline One & $114(31.3)$ & $54(14.8)$ & $30(8.2)$ & 37 (10.2) & 99 (27.2) & $23(6.3)$ & $7(1.9)$ & $364(87.3)$ \\
\hline Two or more & 19 (35.9) & $8(15.1)$ & 7 (13.2) & $4(7.6)$ & $11(20.8)$ & $4(7.6)$ & $0(0.0)$ & $53(12.7)$ \\
\hline
\end{tabular}

Table 4 Binary logistic regression of lifetime stillbirth experience on maternal education $(n=7183)$

\begin{tabular}{|c|c|c|c|c|c|}
\hline \multirow[b]{2}{*}{ Education } & \multirow[b]{2}{*}{$\begin{array}{l}\text { Unadjusted } \\
\text { OR }(95 \% \mathrm{Cl})\end{array}$} & \multicolumn{4}{|l|}{ Adjustment for: } \\
\hline & & $\begin{array}{l}\text { Model 1: core } \\
\text { covariates* } \\
\text { OR }(95 \% \mathrm{Cl})\end{array}$ & $\begin{array}{l}\text { Model 2: } \\
\text { + biomass } \\
\text { fuel use } \\
\text { OR }(95 \% \mathrm{Cl})\end{array}$ & $\begin{array}{l}\text { Model 3: } \\
\text { + unsafe water } \\
\text { consumption } \\
\text { OR }(95 \% \mathrm{Cl})\end{array}$ & $\begin{array}{l}\text { Model 4: + biomass } \\
\text { fuel use and unsafe } \\
\text { water consumption } \\
\text { OR }(95 \% \mathrm{Cl})\end{array}$ \\
\hline None & $1.08(0.73$ to 1.59$)$ & $1.19(0.78$ to 1.82$)$ & & & \\
\hline Lower primary & 1.51 (0.98 to 2.33$)$ & 1.62 (1.04 to 2.52$)$ & $\begin{array}{l}1.51 \text { (0.95 to } \\
2.41)\end{array}$ & 1.57 (1.00 to 2.47$)$ & 1.47 (0.92 to 2.37$)$ \\
\hline Upper primary & $0.86(0.53$ to 1.38$)$ & $0.98(0.60$ to 1.60$)$ & & & \\
\hline Some middle/JSS & 1.10 (0.69 to 1.76$)$ & 1.26 (0.78 to 2.02$)$ & & & \\
\hline $\begin{array}{l}\text { Completed middle/ } \\
\text { JSS }\end{array}$ & $1.06(0.72$ to 1.58$)$ & $1.11(0.74$ to 1.65$)$ & & & \\
\hline Secondary + & 1.00 & 1.00 & 1.00 & 1.00 & 1.00 \\
\hline
\end{tabular}

regression. Lower primary education was associated with a statistically significant $62 \%(\mathrm{OR}=1.62,95 \%$ CI 1.04 to 2.52) increased risk of stillbirth in a lifetime after adjustment for the core covariates. Biomass fuel use and unsafe water consumption mediated $17.7 \%$ and $8.1 \%$ of the observed association of lower primary education on lifetime stillbirth risk. In the joint model, the mediation fraction was $24.2 \%$. No consistent educational gradient was observed.

Online supplementary figure S1 depicts the smoothed curves for OR of stillbirth in a lifetime in relation to maternal years of schooling. Among all mothers, a very flat inverted spoon-shaped smoothed curve was observed. The OR of lifetime stillbirth increased slightly away from the reference level up to about 2.5 years of schooling, and declined slowly afterwards with further schooling. The $95 \%$ confidence band was generally wide especially towards the tail end of the smoothed curve. Among rural dwellers, a more pronounced inverted spoon-shaped smoothed curve was observed. Among urban dwellers, an s-shape smoothed curve with a generally wide $95 \%$ confidence band over the whole range of the maternal schooling years was observed.
For all study participants $(\mathrm{p}=0.4166)$ and urban dwellers $(p=0.6003)$, the non-linearity $\chi^{2}$ was not statistically significant. Among rural dwellers, the non-linearity $\chi^{2}$ was borderline significant $(\mathrm{p}=0.0558)$ thereby indicating possible departure from linearity. In the model adjusting for the mediating effect of biomass fuel use, the decrease in the OR of lifetime stillbirth after 6.5 years of schooling was very gentle. In the model adjusting for the mediating effect of unsafe water consumption, no appreciable change in the smoothed curve was observed and possibly confirms the small mediation fraction estimated in the logistic regression.

\section{DISCUSSION}

We found lower maternal primary education to be associated with a $62 \% \quad(\mathrm{OR}=1.62 ; 95 \%$ CI 1.04 to 2.52) increased lifetime risk of stillbirth. Biomass fuel use and consumption of unsafe water mediated $18 \%$ and $8 \%$ of the observed effects, respectively. Jointly these two exposures explained $24 \%$ of the observed effects. The GAM revealed a very flat inverted spoon-shaped smoothed curve which peaked at low levels of schooling (2-3 years) and confirms the findings from the logistic regression modelling. 


\section{Validity issues}

Selection bias was minimised in the study owing to the population-based nature of the GMHS survey and the high response rate $(97.6 \%)$ achieved. Also the standardised data collection instruments and procedures of DHS surveys including the present, and the extensive training of interviewers guarantees the collection of reliable information from survey participants. On the issue of missing data, of the variables of interest concerned (education, marital status, ethnic group, cooking fuel type and drinking water source), the proportion of respondents with missing data was very low $(<0.04 \%)$.

Educational attainment is a strong determinant of future employment and income, ${ }^{18}{ }^{19}$ and certainly has implications for maternal health and pregnancy outcomes. The potential for outcome measurement bias is reduced in our study even though the outcome of interest was subjectively reported by the respondents. This is because stillbirth is a very traumatic experience that every mother with such an experience can vividly recollect.

Exposure to HAP and drinking water contaminants was assessed based on the primary cooking fuels and main drinking water sources of maternal households. There are limitations with the exposure assessment method applied but they have been widely used in environmental epidemiological studies and shown to be very good proxy measures of exposure. There is nonetheless the potential for exposure misclassification in the study with the direction of bias unclear. It was impossible to ascertain whether cooking fuel choices and drinking water sources of the households remained relatively stable throughout the pregnancies of the mothers interviewed. Regarding cooking fuel choices, it is often the case of households transitioning to fuels higher up the energy ladder with improved socioeconomic conditions and back to their traditional fuels as conditions deteriorate. With regards to drinking water sources, except in situations where communities have been connected to pipe-borne water, household water sources traditionally remain the same irrespective of improvement in socioeconomic conditions. It is possible that households connected to pipe-borne water after years of relying on ground and surface water resources will report use of pipe-borne water as their main drinking water source. This information bias, however, would rather underestimate the true effect.

The study adjusted for the effect of age of respondent, marital status, area of residence (urban vs rural) and ethnicity. We had no information on the smoking status of the mothers, but in Ghana only few women smoke. The 2008 Ghana Demographic and Health Survey ${ }^{20}$ estimated the proportion of women smoking cigarettes and other tobacco products to be $0.4 \%$. Maternal smoking can therefore not be considered as a serious threat to validity in this study. We were unable to examine the confounding effect of prenatal and intrapartum care, maternal nutrition and anthropometry as well as malaria and sexually transmitted infections. However, with regards to infections, it has been suggested by Silver et $a l^{21}$ that they are more clearly associated with early stillbirth (20 weeks) than with late stillbirth (after 28 weeks). With the GMHS survey ascertaining stillbirths with a cut-off point of 7 or more months, we can assume that the associations reported are not likely to be confounded by maternal infections.

\section{Synthesis with previous evidence}

Our study adds to the weight of evidence emanating mostly from high-income countries ${ }^{22-26}$ on the adverse perinatal effects of low maternal educational attainment. We found lower primary education to be associated with a $62 \%$ increased risk of lifetime stillbirth. The smoothing curves also peaked at low levels of schooling (2-3 years) and declined with further schooling. A multicountry study $^{27}$ conducted in six low-income countries and one middle-income country reported a $40 \%(\mathrm{RR}=1.4 ; 95 \% \mathrm{CI}$ 1.2 to 1.5 ) increased risk of stillbirth with no formal maternal schooling. Two recent population-based studies conducted in rural Ghana, ${ }^{28}{ }^{29}$ however, found no association between maternal education and stillbirth. Ha et $a t^{28}$ reported small and statistically insignificant increased odds of antepartum and intrapartum stillbirth with no formal and primary maternal education. Engmann $e t a l^{29}$ reported a much higher increased odds of stillbirth with no formal ( $\mathrm{OR}=1.47 ; 95 \%$ CI 0.94 to 2.29) and primary/JSS (OR=1.48, 95\% CI 0.95 to 2.30) maternal education. These associations were also not statistically significant. A systematic review and meta-analysis of the available evidence on the major risk factors for stillbirth in high-income countries ${ }^{26}$ found low educational attainment $(<10$ years of schooling) to be associated with $70 \%$ ( $\mathrm{OR}=1.7 ; 95 \%$ CI 1.4 to $2.0 ; \mathrm{n}=5)$ increased odds of stillbirth. The findings of our study are consistent with the findings of McClure $e t a l^{27}$ and Flenady $e t a .^{26}$

\section{Causal pathways}

Medical care has been mentioned as the route through which education leads to inequality in stillbirth from placental abruption and cord compression. ${ }^{30}$ Suboptimal care including delayed recognition of medical problems or poor management has been noted to contribute to a significant proportion of stillbirths. ${ }^{31}$ Delayed access of prenatal care services owing to ignorance is very common in developing countries. Also common in developing countries is the inability of mothers to apply the nutritional and health messages received during prenatal visits for improved maternal and fetal health. This situation arises as a result of lack of education or low educational attainment of mothers. According to Galobardes $e t ~ a l,{ }^{32}$ education may affect an individual's cognitive functioning and enable him/her to access appropriate health services, to better communicate with healthcare workers and to be more receptive to health education messages. Stephansson et $a l^{33}$ have also suggested that the socioeconomic differences in the risk of 
stillbirth can be attributed to social differences in seeking care for signs of pathological pregnancy such as reduced fetal movements.

In developing countries, besides access and usage of health services, there are other important pathways through which low educational attainment impacts on perinatal outcomes. Our study is the first to explore the mediating role of environmental factors in the maternal education-stillbirth relationship. Biomass fuel use and unsafe water consumption explained about $18 \%$ and $8 \%$ of the observed effects of low maternal educational attainment on lifetime stillbirth risk. Jointly, they mediated almost a quarter (24\%) of the observed effect. A study in Ghana found the effects of low educational attainment on average birth weight to be substantially $(62 \%)$ mediated by biomass fuel use. ${ }^{34}$ Studies in Ghana, ${ }^{35}{ }^{36}$ Ethiopia, ${ }^{37}{ }^{38}$ Cameroun ${ }^{39}$ and Kenya ${ }^{40}$ have reported educational attainment to be an important determinant of cooking fuel choices of households.

We must mention that the mediation fraction reported is likely to be overestimated and should be interpreted with caution. This is because prenatal and intrapartum care, maternal nutrition and other social factors which we were unable to control in the analysis are associated with educational attainment just as much as fuel and drinking water choices. It is thus possible that biomass fuel use and unsafe water consumption are essentially a proxy for these confounding variables and biasing the causal effect away from null as a result.

\section{CONCLUSIONS}

In conclusion, we provide evidence that in Ghana and similar developing countries, biomass fuel use and unsafe water consumption could be important pathways through which low maternal educational attainment leads to stillbirths. Women with no formal or low education should therefore receive extra care and support, and be alerted to household environmental risks to their pregnancies during prenatal visits. This recommendation could help curb the high stillbirth occurrence in developing countries. According to Goldenberg et $a l^{41}$ each geographical area must understand the local causes of stillbirth, and the contexts in which they occur to enable prevention strategies to be developed and implemented.

Acknowledgements We would like to thank Measure DHS for granting us permission to use the 2007 Ghana Maternal Health Survey data set for this research.

Contributors AKA conceived and designed the study, and performed the data analysis with guidance from SN and JJKJ. AKA wrote the manuscript with SN and JJKJ reviewing drafts for intellectual content. All authors read and approved the final version.

Funding This research received no specific grant from any funding agency in the public, commercial or not-for-profit sectors.

Competing interests None declared.

Ethics approval The Ghana Maternal Health Survey was approved by the Ghana Statistical Service, Ghana Health Service and MEASURE DHS.

Provenance and peer review Not commissioned; externally peer reviewed.
Data sharing statement No additional data are available.

Open Access This is an Open Access article distributed in accordance with the Creative Commons Attribution Non Commercial (CC BY-NC 4.0) license, which permits others to distribute, remix, adapt, build upon this work noncommercially, and license their derivative works on different terms, provided the original work is properly cited and the use is non-commercial. See: http:// creativecommons.org/licenses/by-nc/4.0/

\section{REFERENCES}

1. World Health Organisation. ICD-10: International statistical classification of diseases and health related problems. Geneva: WHO, 1992

2. Stanton $\mathrm{C}$, Lawn JE, Rahman $\mathrm{HZ}$, et al. Stillbirth rates: delivering estimates in 190 countries. Lancet 2006;367:1487-94.

3. McClure EM, Saleem S, Pasha O, et al. Stillbirth in developing countries: a review of causes, risk factors and prevention strategies. J Matern Fetal Neonatal Med 2009;22:183-90.

4. Willinger M, Ko CW, Reddy UM. Racial disparities in stillbirth risk across gestation in the United States. Am j obstet gynecol 2009;201:469.e1-8.

5. Luo ZC, Wilkins R. Degree of rural isolation and birth outcomes. Paediatr Perinat Epidemiol 2008;22:341-9.

6. Spong CY, lams J, Goldenberg R, et al. Disparities in perinatal medicine: preterm birth, stillbirth, and infant mortality. Obstet Gynecol 2011;117:948-55.

7. Spong CY, Reddy UM, Willinger M. Addressing the complexity of disparities in stillbirths. Lancet 2011;377:1635-6.

8. Graham JP, Polizzotto ML. Pit latrines and their impacts on groundwater quality: a systematic review. Environ Health Perspect 2013;121:521-30.

9. Amegah AK, Jaakkola JJK. Household air pollution and the sustainable development goals. Bull World Health Organ 2016;94:215-21.

10. Bonjour $\mathrm{S}$, Adair-Rohani $\mathrm{H}$, Wolf $\mathrm{J}$, et al. Solid fuel use for household cooking: country and regional estimates for 1980-2010. Environ Health Perspect 2013;121:784-90.

11. Amegah AK, Quansah R, Jaakkola JJK. Household air pollution from solid fuel use and risk of adverse pregnancy outcomes: a systematic review and meta-analysis of the empirical evidence. PIOS ONE 2014;9:e113920.

12. Ahmad SA, Sayed $\mathrm{MH}$, Barua $\mathrm{S}$, et al. Arsenic in drinking water and pregnancy outcomes. Environ Health Perspect 2001;109:629-31.

13. von Ehrenstein OS, Guha Mazumder DN, Hira-Smith M, et al. Pregnancy outcomes, infant mortality, and arsenic in drinking water in West Bengal, India. Am J Epidemiol 2006;163:662-9.

14. Bukowski J, Somers G, Bryanton J. Agricultural contamination of groundwater as a possible risk factor for growth restriction or prematurity. J Occup Environ Med 2001;43:377-83.

15. Kramer MS, Seguin L, Lydon J, et al Socioeconomic disparities in pregnancy outcome: why do the poor fare so poorly? Paediatr Perinat Epidemiol 2000;14:194-210.

16. Ghana Statistical Service, Ghana Health Service, Macro International. Ghana Maternal Health Survey 2007. Calverton, MD, USA: GSS, GHS and Macro International, 2009.

17. Judd CM, Kenny DA. Process analysis: estimating mediation in treatment evaluations. Eval Rev 1981;5:602-19.

18. Lynch J, Kaplan G. Socioeconomic position. In: Berkman LF Kawachi I, eds. Social epidemiology. Oxford: Oxford University Press, 2000:13-35.

19. Davey Smith G, Hart C, Hole D, et al. Education and occupational social class: which is the more important indicator of mortality risk? $J$ Epidemiol Community Health 1998;52:153-60.

20. Ghana Statistical Service, Ghana Health Service, ICF Macro. Ghana Demographic and Health Survey 2008. Accra: GSS, GHS, and ICF Macro, 2009.

21. Silver RM, Varner MW, Reddy U, et al. Work-up of stillbirth: a review of the evidence. Am J Obstet Gynecol 2007:196:433-44.

22. Auger N, Delezire $\mathrm{P}$, Harper S, et al. Maternal education and stillbirth: estimating gestational-age-specific and cause-specific associations. Epidemiol 2012;23:247-54.

23. Luque-Fernández MÁ, Lone NI, Gutiérrez-Garitano I, et al. Stillbirth risk by maternal socio-economic status and country of origin: a population-based observational study in Spain, 2007-08. Eur J Public Health 2012;22:524-9.

24. Rom AL, Mortensen LH, Cnattingius S, et al. A comparative study of educational inequality in the risk of stillbirth in Denmark, Finland, 
Norway and Sweden 1981-2000. J Epidemiol Community Health 2012;66:240-6.

25. Luo ZC, Wilkins R, Kramer MS. Effect of neighbourhood income and maternal education on birth outcomes: a population-based study. Can Med Assoc J 2006;174:1415-20.

26. Flenady V, Koopmans L, Middleton P, et al. Major risk factors for stillbirth in high-income countries: a systematic review and meta-analysis. Lancet 2011;377:1331-40.

27. McClure EM, Pasha O, Goudar SS, et al. Epidemiology of stillbirth in low-middle income countries: a Global Network Study. Acta Obstet Gynecol Scand 2011;90:1379-85.

28. Ha YP, Hurt LS, Tawiah-Agyemang C, et al. Effect of socioeconomic deprivation and health service utilisation on antepartum and intrapartum stillbirth: population cohort study from rural Ghana. PLOS ONE 2012;7:e39050.

29. Engmann C, Walega P, Aborigo RA, et al. Stillbirths and early neonatal mortality in rural Northern Ghana. Trop Med Int Health 2012;17:272-82.

30. Savard N, Auger N, Park AL, et al. Educational inequality in stillbirth: temporal trends in Québec from 1981 to 2009. Can J Public Health 2013;104:e148-153.

31. Flenady V, Middleton P, Smith GC, et al. Stillbirths: the way forward in high-income countries. Lancet 2011;377:1703-17.

32. Galobardes B, Shaw M, Lawlor DA, et al. Indicators of socioeconomic position. J Epidemiol Community Health 2006;60:95-101.
33. Stephansson O, Dickman PW, Johansson AL, et al. The influence of socioeconomic status on stillbirth risk in Sweden. Int J Epidemiol 2001;30:1296-301.

34. Amegah AK, Damptey OK, Sarpong GA, et al. Malaria infection, poor nutrition and indoor air pollution mediate socioeconomic differences in adverse pregnancy outcomes in Cape Coast, Ghana. PLOS ONE 2013;8:e69181.

35. Amegah AK, Jaakkola JJ, Quansah R, et al. Cooking fuel choices and garbage burning practices as determinants of birth weight: a cross-sectional study in Accra, Ghana. Environ Health 2012;11:78.

36. Owusu Boadi K, Kuitunen M. Factors affecting the choice of cooking fuel, cooking place and respiratory health in the Accra metropolitan area, Ghana. J Biosoc Sci 2006;38:403-12.

37. Mekonnen A, Köhlin G. Determinants of household fuel choice in major cities in Ethiopia. Environment for development discussion paper series. 2008;DP:8-18.

38. Alem $\mathrm{Y}$, Beyene $A D$, Köhlin $\mathrm{G}$, et al. Household fuel choice in urban Ethiopia. A random effects multinomial logit analysis. Environment for development discussion paper series. 2013;DP:13-12.

39. Njong AM, Johannes TA. An analysis of domestic cooking energy choices in Cameroon. Eur J Soc Sci 2011;20:336-47.

40. Pundo MO, Fraser GCG. Multinomial logit analysis of household cooking fuel choice in rural Kenya: a case of Kisumu district. Agrekon 2006;45:24-37.

41. Goldenberg RL, McClure EM, Bhutta ZA, et al. Stillbirths: the vision for 2020. Lancet 2011;377:1798-805. 